\title{
Solubility Enhancement of Simvastatin through Surfactant Addition for Development of Hydrophobic Drug-Loaded Gelatin Hydrogel
}

\author{
Niswati Fathmah Rosyida ${ }^{1,2}$, Pinandi Sri Pudyani ${ }^{1}$, Akhmad Kharis Nugroho ${ }^{3}$, \\ Ika Dewi Ana ${ }^{4, *}$, and Teguh Ariyanto ${ }^{5, * *}$ \\ ${ }^{1}$ Department of Orthodontics, Faculty of Dentistry, Universitas Gadjah Mada, Yogyakarta 55281, Indonesia \\ ${ }^{2}$ Graduate School of Dental Science, Faculty of Dentistry, Universitas Gadjah Mada, Yogyakarta 55281, Indonesia \\ ${ }^{3}$ Department of Pharmaceutics, Faculty of Pharmacy, Universitas Gadjah Mada, Yogyakarta 55281, Indonesia \\ ${ }^{4}$ Department of Biomedicine, Faculty of Dentistry, Universitas Gadjah Mada, Yogyakarta 55281, Indonesia \\ ${ }^{5}$ Department of Chemical Engineering, Faculty of Engineering, Universitas Gadjah Mada, Yogyakarta 55281, Indonesia
}

\section{*Corresponding author:}

tel: +62-274-6492171

email:ikadewiana@ugm.ac.id*;

teguh.ariyanto@ugm.ac.id*

Received: August 6, 2018

Accepted: October 9, 2018

DOI: $10.22146 /$ ijc.38153

\begin{abstract}
This study aims to synthesize simvastatin hydrogel as drug delivery system with surfactant addition for improving solubility of simvastatin. Surfactants used in the study were the zwitterionic amino acid of arginine and nonionic surface-active agent of polysorbate 80. The solubility study was conducted by pouring of an excess mass of simvastatin into the solution of a surfactant in a conical flask. The sample was shaken up to $72 \mathrm{~h}$ in a mechanical water bath shaker at a varied temperature of 25,40 , and $50{ }^{\circ} \mathrm{C}$. The amount of drug dissolved in solution was analyzed by UV/Visible spectrophotometer at 238 $n \mathrm{~m}$. The results showed that the simvastatin solubility is profoundly influenced by the surfactant type, surfactant concentration, and temperature. Polysorbate 80 exhibited as a better surfactant than arginine and an enhancement up to 1400 times, in respect of without any addition of a surfactant, was observed. Based on the solubility study, simvastatin-loaded gelatin hydrogel composite was formulated and the characterization (FTIR and SEM) showed the successful impregnation. The hydrogel microparticles presented a sustained release profile.
\end{abstract}

Keywords: hydrogel; simvastatin; solubility; surfactant

\section{- INTRODUCTION}

Simvastatin is one of the drugs with low solubility to lower blood cholesterol. Recently, simvastatin has been reported to have an anabolic effect for accelerating bone regeneration [1-2]. The mechanism of simvastatin on bone regeneration is through reducing osteoclast differentiation [3], suppressing osteoblasts apoptosis [4], and inducing osteogenesis [5]. Simvastatin administrated orally will be retained in the liver by $95 \%$ and only $5 \%$ are systemically distributed [6-7]. Therefore, to obtain statin effects on the bone requires high doses that could potentially increase the toxicity and side effect of the drug such as rhabdomyolysis [8]. Local administration of simvastatin through hydrogel system can be used to overcome the hepatotropic nature of simvastatin and to enhance effectivity of the drug for bone regeneration [9].

The hydrogel is a drug carrier polymer which crosslinked with a water-soluble polymer [10]. The advantages of the hydrogel are biocompatible, can sustain release of the drug [11], easy to control its properties [12], and can be made from natural material like gelatin. However, hydrogels are also less suitable for hydrophobic drugs because of the difficulty of achieving drug homogeneity in the hydrogel matrix. The enhancement of drug solubility is one of the most

Niswati Fathmah Rosyida et al. 
challenging aspects in the drug development process, especially for drug delivery system application [13].

Simvastatin has low solubility in water thus limiting dispersion of this hydrophobic drug in a hydrogel. It has been reported that solubility of simvastatin in water was only $7.25 \times 10^{-3} \mathrm{mg} \mathrm{mL}^{-1}$ [14]. The chemical structure of simvastatin with naphthalene groups, two cyclic carbons, and cyclic lactones causes simvastatin has nonpolar properties. Therefore, the drug has a low solubility in a polar solvent, such as water, although it has an active hydroxyl group capable of forming a hydrogen bond with a water molecule [15-16]. The molecular structure of simvastatin is shown in Fig. 1. The direct loading of simvastatin in gelatin as natural material to make hydrogel will not produce the homogeneity of the dispersion due to particle agglomeration [17]. Therefore, it is necessary to modify the condition of water solution to enhance the solubility of simvastatin, e.g. using a surfactant. Enhancement of simvastatin solubility is proposed to increase the effectiveness and bioavailability of the drug.

This paper presents a comprehensive study of improving solubility of simvastatin with the addition of a surfactant, determining its thermodynamic parameters, and developing a controlled drug delivery system by loading simvastatin into gelatin hydrogel. Two types of surfactant were employed, i.e. arginine and polysorbate 80. Solubility enhancement using arginine was based on our previous work [18] which is expanded in this study using polysorbate 80 . Arginine was studied since it is the best amino acid that improves solubility of a hydrophobic drug like while polysorbate 80 as the non-ionic surfactant is typically used as an emulsion of a hydrophobic drug [19]. Meanwhile, both surfactants are known to be safe chemicals to be employed to human [20].

\section{- EXPERIMENTAL SECTION}

\section{Materials}

Simvastatin (SIM) was purchased from Sigma Aldrich, Singapore, (pharmaceutical grade) as an active substance of hydrophobic drug. The surfactants employed were arginine (ARG) and polysorbate 80 (POL 80),

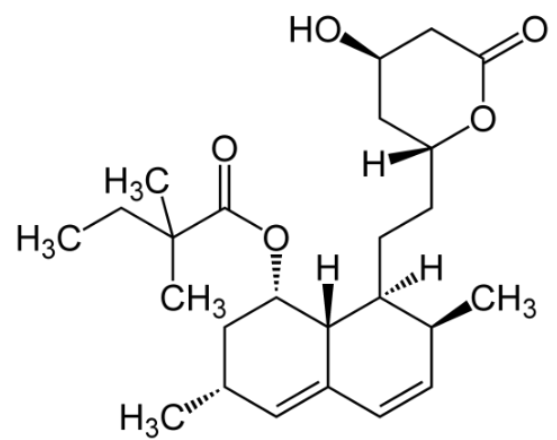

Fig 1. Molecular structure of simvastatin

available in a pharmaceutical grade provided by Sigma Aldrich, Singapore. Type B gelatin (GEL) was obtained from Nitta Gelatin Inc. (Osaka, Japan) as the polymer for preparing a hydrogel.

\section{Procedure}

\section{Solubility study of simvastatin with surfactant addition}

Surfactant solutions in the range of $0.01-1 \mathrm{~mol} \mathrm{~L}^{-1}$ were prepared by dissolving an exact mass of surfactant into $100 \mathrm{~mL}$ of water in the Erlenmeyer tube. The $\mathrm{pH}$ of the solution was controlled in $\mathrm{pH} 7$ for ARG and $\mathrm{pH} 3$ for POL 80 solutions. Excessive amounts of SIM were added to each Erlenmeyer containing the specified molar solutions of ARG or POL 80. To perform isotherm solubility studies, all conical flasks filled by homogenous mixtures of surfactant and SIM were placed in a water bath shaker under controlled temperature conditions of 25,40 , and $50^{\circ} \mathrm{C}$. The mixtures were shaken up to $72 \mathrm{~h}$ to ensure that equilibrium condition was achieved. After the incubation period, approx. $2 \mathrm{~mL}$ of sample liquid was drawn from the suspension through $0.46 \mu \mathrm{m}$ PTFE syringe filter and absorbance was measured by the UVVisible spectrophotometer (UV 1800, Shimadzu, Japan) at the position of $238 \mathrm{~nm}$. A standard curve method was then employed to convert the absorbance to concentration. The result was prepared by a linear curve obtained from the different exact mass of SIM dissolved in ethanol as a solvent.

\section{Evaluation of thermodynamic properties}

Thermodynamic property of Gibbs free energy $\left(\Delta G, \mathrm{~J} \mathrm{~mol}^{-1}\right)$ of the solubility of SIM in water with the 
addition of surfactant was evaluated with Equation (1) [16].

$$
\Delta \mathrm{G}=-2.303 \mathrm{RT} \log \mathrm{S}_{\mathrm{s}} / \mathrm{S}_{\mathrm{w}}
$$

where $S_{s}$ and $S_{w}$ are the solubilities of SIM in a solvent with surfactant and pure water, respectively $\left(\mathrm{mol} \mathrm{L}^{-1}\right), \mathrm{R}$ is the gas constant $\left(8.314 \mathrm{~J} \mathrm{~mol}^{-1} \mathrm{~K}^{-1}\right)$, and $\mathrm{T}$ is the temperature (K).

The enthalpy $\left(\Delta \mathrm{H}, \mathrm{J} \mathrm{mol}^{-1}\right)$ and entropy $\left(\Delta \mathrm{S}, \mathrm{J} \mathrm{mol}^{-1}\right)$ was determined by van't Hoff formula (Equation (2)) and the correlation of three equilibrium characters (Equation (3)) [16].

$$
\frac{\mathrm{d} \ln \left(\mathrm{S}_{\mathrm{s}} / \mathrm{S}_{\mathrm{w}}\right)}{\mathrm{dT}}=\frac{-\Delta \mathrm{H}}{\mathrm{RT}^{2}}
$$

$\Delta \mathrm{G}=\Delta \mathrm{H}-\mathrm{T} \Delta \mathrm{S}$

\section{Preparation of simvastatin-loaded gelatin hydrogel}

The hydrogel of SIM was prepared by dissolving 7\% $\mathrm{w} / \mathrm{v}$ concentration of GEL powder in $100 \mathrm{~mL}$ of distilled water in a beaker and waited until it was swelling for one hour. Subsequently, GEL was stirred in a water bath at $40{ }^{\circ} \mathrm{C}$ until homogeneous. On the other hand, a complex of SIM and surfactant was prepared by dissolving SIM into the surfactant solution using a magnetic stirrer for $2 \mathrm{~h}$ with a temperature of $50^{\circ} \mathrm{C}$. Complex SIM-surfactant was added to GEL solution and then stirred at $40{ }^{\circ} \mathrm{C}$ for $3 \mathrm{~h}$. The $\mathrm{pH}$ of GEL-SIM solution was adjusted at 7.4 by adding sodium chloride $(\mathrm{NaCl})$. The GEL-SIM solution was cast into polypropylene mold. Subsequently, the specimen was put in a freezer at a temperature of $30{ }^{\circ} \mathrm{C}$ for $24 \mathrm{~h}$. The frozen sample then was placed in the freeze dryer for $24 \mathrm{~h}$. Then, the sample was wrapped in parchment paper and aluminum foil and inserted into a vacuum oven at $140{ }^{\circ} \mathrm{C}$ for $72 \mathrm{~h}$ to produce crosslinking by dehydrothermal treatment method (DHT). Finally, the hydrogel block matrix was blended to obtain microparticles with 150-250 $\mu \mathrm{m}$ size.

\section{Hydrogel characterizations}

Swelling index of hydrogel was measured through a hydration process. First, the initial weight of hydrogel was measured by an electric balance $\left(\mathrm{w}_{1}\right)$. Subsequently, the hydrogel was impregnated with $100 \mu \mathrm{L}$ of distilled water for $24 \mathrm{~h}$. The final weight of hydrogel was measured $\left(\mathrm{w}_{2}\right)$ after the excessive water removed with filter paper. The swelling index was defined by the ratio of an increased mass after immersion $\left(\mathrm{w}_{2}-\mathrm{w}_{1}\right)$ and the initial mass of hydrogel $\left(\mathrm{w}_{1}\right)$ as shown in the Equation (4).

Swelling index $(-)=\frac{\mathrm{w}_{2}-\mathrm{w}_{1}}{\mathrm{w}_{1}}$

To determine the functional and qualitative groups of hydrogel microparticles, the Fourier Transform Infrared Spectroscopy (FTIR) test was performed by NICOLET iS10 (Thermo scientific, USA). A material pellet was prepared by mixing of hydrogel with $\mathrm{KBr}$ (sample:KBR =1:50). The translucent film was recorded over a range of 4000 to $400 \mathrm{~cm}^{-1}$. The surface morphology of hydrogel microparticles was observed by scanning electron microscope (SEM) by JSM-6510 LA (JEOL, Japan) at an accelerating voltage of $15 \mathrm{kV}$.

The release profile method of simvastatin from gelatin hydrogel used refers to Tanigo method [21]. The hydrogel microparticle was placed in $1 \mathrm{~mL}$ of PBS. The release test was performed at $37^{\circ} \mathrm{C}$ and the phosphate buffer saline (PBS) was exchanged at different time intervals. After centrifugation, the supernatant of PBS was collected and determined by UV/Vis absorption spectroscopy at a wavelength of $238 \mathrm{~nm}$. Simvastatin concentration was evaluated by using the calibration curve method.

\section{- RESULTS AND DISCUSSION}

\section{Solubility of Simvastatin in the Surfactant Solution}

Solubility study of SIM in water was conducted by introducing surfactant at different concentrations. Fig. 2 exhibits the solubility of SIM as a function of POL 80 concentration and temperature. As a reference, the solubility of SIM in water is approx. $0.01 \mathrm{mmol} \mathrm{L}^{-1}$ at $25{ }^{\circ} \mathrm{C}$ which is in agreement with the literature $[14,21]$. The polysorbate 80 concentration was set to a maximum of 5 wt.\% (ca. $2.1 \times 10^{-4} \mathrm{~mol} \mathrm{~L}^{-1}$ ) for a safe condition when using this compound in drug formulation [10]. From the figure, it can be seen a sharp increase in the SIM solubility when increasing surfactant concentration. At the highest concentration of POL 80 of $2.1 \times 10^{-4} \mathrm{~mol} \mathrm{~L}^{-1}$, the solubility of SIM is $7.96\left(25^{\circ} \mathrm{C}\right)$, $9.08\left(40^{\circ} \mathrm{C}\right)$ and $12.50\left(50^{\circ} \mathrm{C}\right) \mathrm{mmol} \mathrm{L}^{-1}$. These values 
are remarkably higher when compared to those values of the SIM solubility using arginine (only up to $0.16 \mathrm{mmol}$ $\mathrm{L}^{-1}$ at $0.1 \mathrm{~mol} \mathrm{~L}^{-1}$ arginine concentration and $40^{\circ} \mathrm{C}$ ) [18]. The enhancement of solubility is up to 1400 times $(2.1 \times$ $10^{-4} \mathrm{~mol} \mathrm{~L}^{-1}$ of polysorbate 80 concentration and $50{ }^{\circ} \mathrm{C}$ temperature).

\section{Thermodynamic Properties of Simvastatin Solubility Enhancement}

To obtain more fundamental of the solubility characters of SIM when using a surfactant, thermodynamic parameters were evaluated included $\Delta \mathrm{G}$, $\Delta \mathrm{H}$, and $\Delta \mathrm{S}$. Table 1 showed the parameters when ARG was employed (solubility data are taken from Niswati et al. [18]). The temperature was limited up to $40{ }^{\circ} \mathrm{C}$ to maintain a stability of arginine. The values of Gibbs free energy are in between -200 and -7100 $\mathrm{J} \mathrm{mol}^{-1}$. The more negative value indicates, the more favorable of SIM in the solution. It can be seen that the value becomes more negative when increasing concentration and temperature. Furthermore, enthalpy $(\Delta \mathrm{H})$ displays a positive value for all conditions suggesting that the solubilization of SIM is an endothermic suggesting that the solubility of SIM is more favorable at high temperature.

Thermodynamic properties of the SIM-POL 80 water system are summarized in Table 2. These parameters have the same tendency when compared to ARG system. However, the value of $\Delta \mathrm{G}$ is remarkably more negative (up to $-20.000 \mathrm{~J} \mathrm{~mol}^{-1}$ at $50^{\circ} \mathrm{C}$ ) concerning

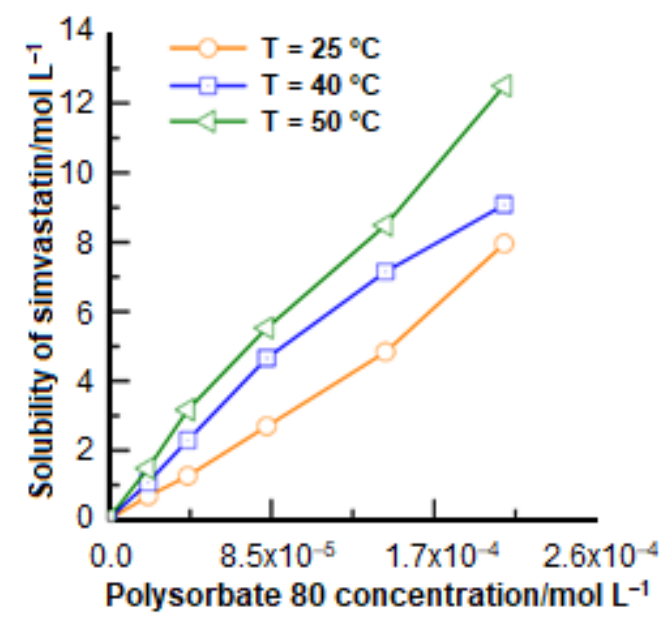

Fig 2. The solubility of simvastatin as a function of temperature in polysorbate 80 solution

Table 1. Thermodynamic properties of the solubility of simvastatin in various concentration of arginine

\begin{tabular}{|c|c|c|c|c|c|c|}
\hline \multirow[b]{2}{*}{$\begin{array}{l}\text { [Arginine], } \\
\text { mol L }^{-1}\end{array}$} & \multicolumn{2}{|c|}{$25^{\circ} \mathrm{C}$} & \multicolumn{2}{|c|}{$40^{\circ} \mathrm{C}$} & \multirow[b]{2}{*}{$\begin{array}{c}\Delta \mathrm{S} \\
\mathrm{J} \mathrm{mol}^{-1} \mathrm{~K}^{-1}\end{array}$} & \multirow[b]{2}{*}{$\begin{array}{c}\Delta \mathrm{H}, \\
\mathrm{J} \mathrm{mol}^{-1}\end{array}$} \\
\hline & $\begin{array}{c}\text { SIM solubility, } \\
\text { mmol L }^{-1}\end{array}$ & $\begin{array}{l}\Delta \mathrm{G}, \\
\mathrm{J} \mathrm{mol}^{-1}\end{array}$ & $\begin{array}{c}\text { SIM solubility, } \\
\text { mmol L }^{-1}\end{array}$ & $\begin{array}{c}\Delta G, \\
\mathrm{~J} \mathrm{~mol}^{-1}\end{array}$ & & \\
\hline 0.000 & 0.009 & - & 0.011 & - & - & - \\
\hline 0.010 & 0.010 & -201 & 0.049 & -3941 & 249 & 74132 \\
\hline 0.020 & 0.011 & -519 & 0.073 & -4988 & 298 & 88297 \\
\hline 0.050 & 0.039 & -3676 & 0.098 & -5772 & 140 & 37992 \\
\hline 0.070 & 0.059 & -4681 & 0.118 & -6247 & 104 & 26441 \\
\hline 0.100 & 0.073 & -5201 & 0.163 & -7095 & 126 & 32445 \\
\hline
\end{tabular}

Table 2. Thermodynamic properties of the solubility of simvastatin in various concentration of polysorbate 80

\begin{tabular}{|c|c|c|c|c|c|c|c|c|}
\hline \multirow{2}{*}{$\begin{array}{l}\text { [Polysorbate } 80] \\
\mathrm{mol} \mathrm{L}^{-1}\end{array}$} & \multicolumn{2}{|c|}{$25^{\circ} \mathrm{C}$} & \multicolumn{2}{|l|}{$40^{\circ} \mathrm{C}$} & \multicolumn{2}{|c|}{$50^{\circ} \mathrm{C}$} & \multirow{2}{*}{$\begin{array}{c}\Delta \mathrm{S} \\
\mathrm{J} \mathrm{mol}^{-1} \mathrm{~K}^{-1}\end{array}$} & \multirow{2}{*}{$\begin{array}{c}\Delta \mathrm{H} \\
\mathrm{J} \mathrm{mol}^{-1}\end{array}$} \\
\hline & $\begin{array}{l}\text { SIM solubility, } \\
\text { mmol L }^{-1}\end{array}$ & $\begin{array}{l}\Delta \mathrm{G} \\
\mathrm{J} \mathrm{mol}^{-1}\end{array}$ & $\begin{array}{l}\text { SIM solubility, } \\
\text { mmol L }^{-1}\end{array}$ & $\begin{array}{l}\Delta \mathrm{G} \\
\mathrm{J} \mathrm{mol}^{-1}\end{array}$ & $\begin{array}{l}\text { SIM solubility, } \\
\text { mmol L }^{-1}\end{array}$ & $\begin{array}{l}\Delta \mathrm{G} \\
\mathrm{J} \mathrm{mol}^{-1}\end{array}$ & & \\
\hline 0 & 0.009 & - & 0.011 & - & 0.032 & - & - & - \\
\hline $2.07 \times 10^{-5}$ & 0.684 & -10758 & 1.081 & -12016 & 1.484 & -13741 & 119 & 41248 \\
\hline $4.13 \times 10^{-5}$ & 1.265 & -12283 & 2.290 & -13971 & 3.169 & -15781 & 140 & 24822 \\
\hline $8.27 \times 10^{-5}$ & 2.696 & -14159 & 4.658 & -15820 & 5.527 & -17275 & 125 & 29428 \\
\hline $1.45 \times 10^{-5}$ & 4.835 & -15607 & 7.149 & -16936 & 8.490 & -18429 & 113 & 23005 \\
\hline $2.07 \times 10^{-5}$ & 7.959 & -16843 & 9.080 & -17559 & 12.499 & -19468 & 105 & 18047 \\
\hline
\end{tabular}



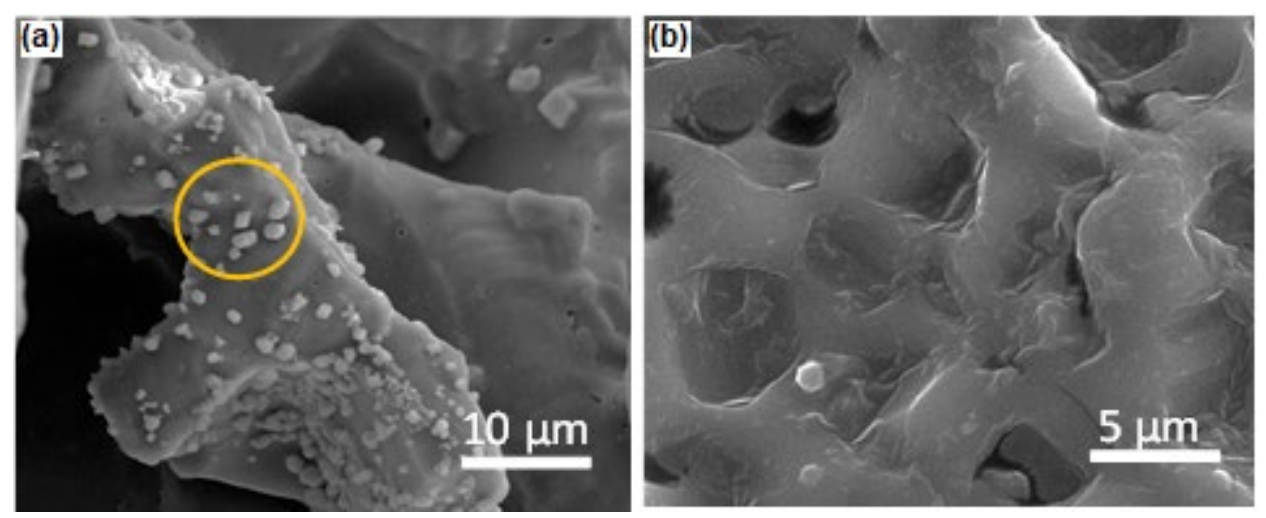

Fig 3. SEM images of (a) GEL-SIM hydrogel and (b) GEL-POL-SIM hydrogel

a minimum value when using ARG. This indicates that POL 80 is more benign to SIM. Moreover, values of the enthalpy are quite low in the range $18000-41000 \mathrm{~J} \mathrm{~mol}^{-1}$ meaning an ease ability of SIM to dissolve in POL 80.

\section{The Properties and Release Profiles of Simvastatin- Loaded Hydrogel Microparticles}

The success of enhancing SIM solubility in water solution by using surfactant was employed to formulate drug-loaded gelatin hydrogel. Based on the solubility study, it is expected that $6 \mathrm{wt} . \%$ of SIM can be loaded to hydrogel when employing POL 80 surfactant, respectively. The use of very small amounts of SIM will affect the effectiveness of drugs in bone regeneration, especially for osteoblast proliferation [5]. Therefore POL 80 was selected for formulating hydrogel microparticle because in this study the surfactant was known to be able to dissolve larger amounts of SIM.

The morphologies of GEL-SIM and SIM-loaded hydrogel were then observed by using microscopy methods. It was shown that both materials display a granule-like structure (data not shown, observed with a stereomicroscope (Olympus SZX7, Japan). The microparticles obtained showed a relatively homogeneous size ca. $200 \mu \mathrm{m}$. The SEM images of GEL-SIM and GELSIM-POL hydrogels are shown in Fig. 3(a) and 3(b). The images show that in the GEL-SIM hydrogel exhibits agglomeration of simvastatin particles (yellow circle, see Fig. 3(a)), while a homogeneous dispersion of simvastatin is observed in GEL-SIM-POL hydrogel (see Fig. 3(b)). This highlights a positive impact of the POL 80 addition

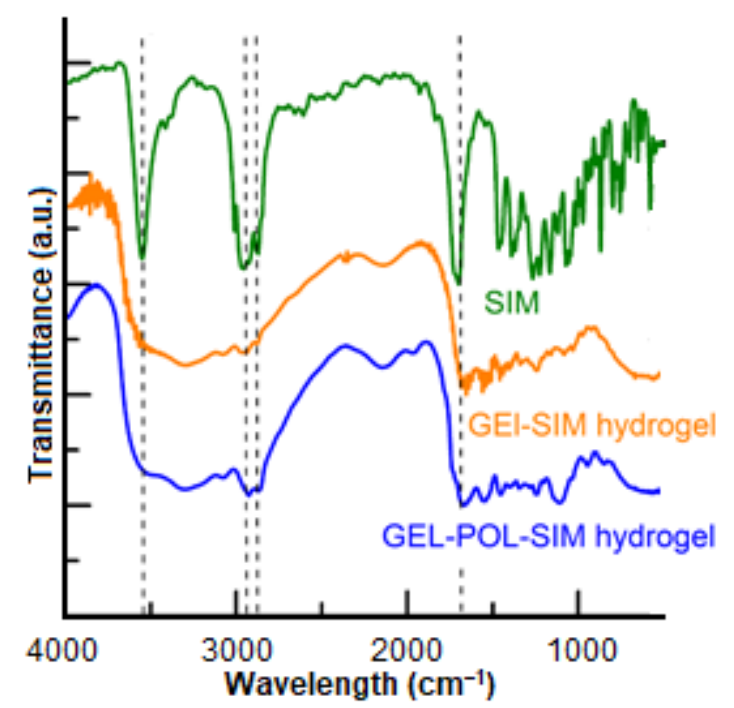

Fig 4. FTIR signals of substances and simvastatin-loaded hydrogels

on hydrogel formulation. Surfactant improves the dissolution of lipophilic drugs like SIM in water and increases the rate of disintegration of solid into finer particles [13]. This result was in agreement to the previous study of using tween 80 as a surfactant on polyvinyl alcohol-simvastatin hydrogel for topical application [18].

To study the successful loading of SIM, the FTIR study was performed. FTIR profiles of GEL-SIM and GEL-POL 80-SIM hydrogels are shown in Fig. 4. Simvastatin, as an individual scan, exhibits clearly hydroxyl (-OH) at ca. $3550 \mathrm{~cm}^{-1}$ peaks, alkyl (-RH) at ca. $3000 \mathrm{~cm}^{-1}$ peaks and alkene $(\mathrm{C}=\mathrm{C})$ at $\mathrm{ca} .1700 \mathrm{~cm}^{-1}$ peak of functional groups. When simvastatin was loaded in 


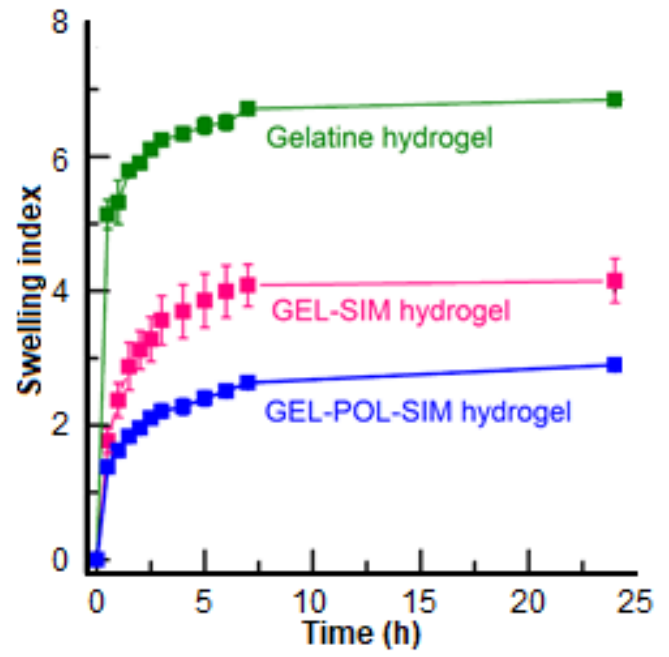

Fig 5. Swelling index of simvastatin-loaded hydrogel and the reference of only gelatin hydrogel

the hydrogel system, the spectra of SIM (-OH, $-\mathrm{RH}$, and $\mathrm{C}=\mathrm{C}$ ) are seen (see the dashed line in Fig. 4). These peaks are typically not shown in the gelatin or polysorbate FTIR spectra. Hence, this indicates the presence of SIM in the hydrogel system.

To evaluate the hydrogel character when in contact with water, the swelling ratio index was determined. The swelling ratio index of hydrogels as a function of impregnating time is shown in Fig. 5. There were significant differences between the hydrogels. Gelatinsimvastatin hydrogel exhibits higher swelling than the GEL-POL-SIM hydrogel. These results can be affected by the interaction between the hydrogel composing materials. Yasasvini et al. stated that the formulation and the degree of cross-linking change the swelling index of the hydrogel. The more degree of cross-linking will reduce the swelling index of hydrogel [22]. The addition of POL 80 improves the solubility of SIM. Therefore, simvastatin can be mixed homogeneously in the hydrogel matrix dan adequately binding with gelatin as hydrogel carrier. The swelling ratios in the groups increased continuously and reached equilibrium after $7 \mathrm{~h}$. In the GEL-SIM hydrogel, it was seen that the standard deviation in the samples was higher than the GEL-POL-SIM. The structure of hydrogel without surfactant addition was less homogeneous as the result of the low dispersion of SIM. This swelling corroborates morphological findings in this study.

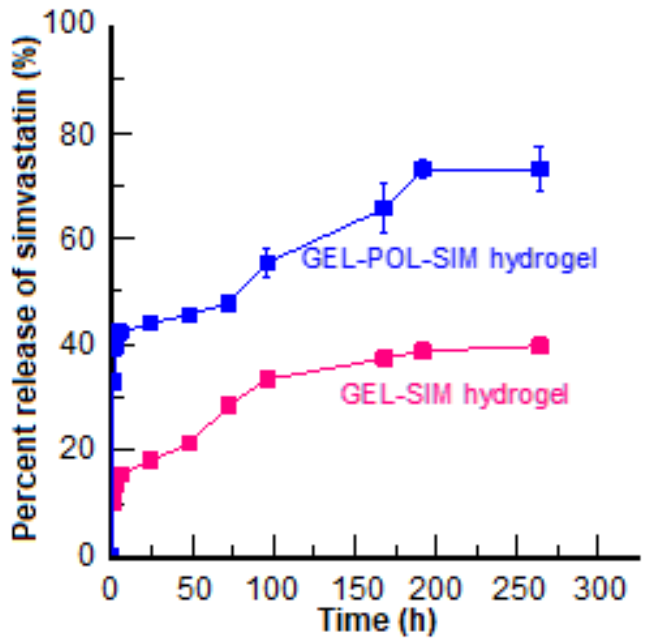

Fig 6. Drug release profile of simvastatin loaded hydrogel

The release of simvastatin from gelatin hydrogel was shown in Fig. 6. In the presence of polysorbate 80, the cumulative release of simvastatin from hydrogel was approximately $74 \%$. While hydrogel simvastatin without surfactant, simvastatin release was only $40 \%$. This result indicated that the formulation using a surfactant which increases solubility would affect the release of active drug from the system. It was reported that solubility of the drug is one of a crucial factor for developing a system of the drug [13]. Therefore, this system could be chosen to improve the effectivity of simvastatin in a local delivery system [23].

\section{- CONCLUSION}

The solubility of simvastatin can be enhanced by the addition of arginine or polysorbate in water as a surfactant. The study showed that concentrations of surfactants and temperatures of solution have significant effects on the simvastatin solubility. The effect of polysorbate 80 on the solubility is strongly noticed when compared to using arginine system. The highest increase of a 1400-times enhancement of the simvastatin solubility was obtained in this study when using conditions of $2.1 \times 10^{-4} \mathrm{~mol} \mathrm{~L}^{-1}$ polysorbate 80 concentration and $50{ }^{\circ} \mathrm{C}$ temperature. This positive influence of polysorbate 80 was further used to formulate simvastatin-loaded hydrogel based on gelatin. Characterization of gelatin-polysorbate-simvastatin 
hydrogel involves the morphology, swelling index and FTIR showed a successful preparation of hydrogel microparticles. Furthermore, the release test showed a positive impact of the higher dissolution of simvastatin when employing a surfactant of polysorbate 80 . Therefore, this formulation could be chosen to deliver simvastatin for bone regenerating purpose.

\section{- ACKNOWLEDGMENTS}

The authors gratefully acknowledge the funding of the Ministry of Research, Technology and Higher Education of the Republic of Indonesia (MENRISTEKDIKTI) through Penelitian Fundamental 2017 (Grant No. 2235/UN1.P.III/DIT-LIT/LT/2017) and Penelitian Dasar Unggulan Perguruan Tinggi 2018 (Grant No. 159/UN1/DITLIT/DIT-LIT/LT/2018).

\section{- REFERENCES}

[1] Garrett, I.R., and Mundy, G.R., 2002, The role of statins as potential targets for bone formation, Arthritis Res., 4 (4), 237-240.

[2] Ayukawa, Y., Yasukawa, E., Moriyama, Y., Ogino, Y., Wada, H., Atsuta, I., and Koyano, K., 2009, Local application of statin promotes bone repair through the suppression of osteoclasts and the enhancement of osteoblasts at bone-healing sites in rats, Oral Surg. Oral Med. Oral Pathol. Oral Radiol. Endod., 107 (3), 336-342.

[3] Tsubaki, M., Satou, T., Itoh, T., Imano, M., Yanae, M., Kato, C., Takagoshi, R., Komai, M., and Nishida, S., 2012, Bisphosphonate- and statin-induced enhancement of OPG expression and inhibition of CD9, M-CSF, and RANKL expressions via inhibition of the Ras/MEK/ERK pathway and activation of p38MAPK in mouse bone marrow stromal cell line ST2, Mol. Cell. Endocrinol., 361 (1-2), 219-231.

[4] Kaji, H., Naito, J., Inoue, Y., Sowa, H., Sugimoto, T., and Chihara, K., 2008, Statin suppresses apoptosis in osteoblastic cells: Role of transforming growth factor- $\beta$-Smad3 pathway, Horm. Metab. Res., 40 (11), 746-751.

[5] Chen, P.Y., Sun, J.S., Tsuang, Y.H., Chen, M.H., Weng, P.W., and Lin, F.H., 2010, Simvastatin promotes osteoblast viability and differentiation via Ras/Smad/Erk/BMP-2 signaling pathway, Nutr. Res., 30 (3), 191-199.

[6] Schachter, M., 2005, Chemical, pharmacokinetic and pharmacodynamic properties of statins: An update, Fundam. Clin. Pharmacol., 19 (1), 117-125.

[7] Kheirallah, M., and Almeshaly, H., 2016, Simvastatin, dosage and delivery system for supporting bone regeneration, an update review, J. Oral Maxillofac. Surg. Med. Pathol., 28 (3), 205-209.

[8] Matsuyama, K., Nakagawa, K., Nakai, N., Konishi, Y., Nishikita, M., Tanaka, H., and Uchida, T., 2002, Evaluation of myopathy risk for HMG-CoA reductase inhibitors by urethane infusion method, Biol. Pharm. Bull., 25 (3), 346-350.

[9] Oryan, A., Kamali, A., and Moshiri, A., 2015, Potential mechanisms and applications of statins on osteogenesis: Current modalities, conflicts and future directions, J. Controlled Release, 215, 12-24.

[10] Kaur, G., and Mehta, S.K., 2017, Developments of Polysorbate (Tween) based microemulsions: Preclinical drug delivery, toxicity and antimicrobial applications, Int. J. Pharm., 529 (1-2), 134-160.

[11] Kim, Y.H., and Tabata, Y., 2015, Dual-controlled release system of drugs for bone regeneration, $A d v$. Drug Deliv. Rev., 94, 28-40.

[12] Hoare, T.R., and Kohane, D.S., 2008, Hydrogels in drug delivery: Progress and challenges, Polymer, 49 (8), 1993-2007.

[13] Savjani, K.T., Gajjar, A.K., and Savjani, J.K., 2012, Drug solubility: Importance and enhancement techniques, ISRN Pharm., 2012, 195727.

[14] Yan, J., Yin, Q., Jiang, C., Gong, J., Zhang, M., Wang, Y., Hou, B., and Hao, H., 2015, Solution thermodynamics of simvastatin in pure solvents and binary solvent mixtures, Fluid Phase Equilib., 406, 77-90.

[15] Sirtori, C.R., 2014, The Pharmacology of statins, Pharmacol. Res., 88, 3-11.

[16] Troy, D.B., and Beringer, P., 2006, Remington: The Science and Practice of Pharmacy, Lippincott Williams \& Wilkins, Philadelphia, US. 
[17] Jia, Z., Zhang, Y., Chen, Y.H., Dusad, A., Yuan, H., Ren, K., Li, F., Fehringer, E.V., Purdue, P.E., Goldring, S.R., Daluiski, A., and Wang, D., 2015, Simvastatin prodrug micelles target fracture and improve healing, J. Controlled Release, 200, 23-34.

[18] Rosyida, N.F., Ariyanto, T., Pudyani, P.S., and Ana, I.D., 2018, Preparation of simvastatin hydrogel through arginine addition for drug delivery system, MATEC Web. Conf., 156, 01002.

[19] Hirano, A., Kameda, T., Arakawa, T., and Shiraki, K., 2010, Arginine-assisted solubilization system for drug substances: Solubility experiment and simulation, $J$. Phys. Chem. B, 114 (42), 13455-13462.

[20] Wolf, R.B., Cavins, J.F., Kleiman, R., and Black, L.T., 1982, Effect of temperature on soybean seed constituents: Oil, protein, moisture, fatty acids, amino acids and sugars, J. Am. Oil Chem. Soc., 59 (5), 230-232.

[21] Tanigo, T., Takaoka, R., and Tabata, Y., 2010, Sustained release of water-insoluble simvastatin from biodegradable hydrogel augments bone regeneration, J. Controlled Release, 143 (2), 201-206.

[22] Yasasvini, S., Anusa, R., Vedhahari, B., Prabhu, P., and Ramyadevi, D., 2016, Topical hydrogel matrix loaded with simvastatin microparticles for enhanced wound healing activity, Mater. Sci. Eng., C, 72, 160-167.

[23] Thambi, T., Li, Y., and Lee, D.S., 2017, Injectable hydrogels for sustained release of therapeutic agents, J. Controlled Release, 267, 57-66. 